\title{
Roles of Ubiquitination and SUMOylation in the Regulation of Angiogenesis
}

\author{
Andrea Rabellino ${ }^{1 \star}$, Cristina Andreani ${ }^{2}$ and Pier Paolo Scaglioni ${ }^{2}$
}

\author{
${ }^{1}$ QIMR Berghofer Medical Research Institute, Brisbane City, Queensland, Australia. \\ ${ }^{2}$ Department of Internal Medicine, Hematology and Oncology; University of Cincinnati, \\ Cincinnati, $\mathrm{OH}$, USA. \\ *Correspondence: andrea.rabellino@qimrberghofer.edu.au
}

https://doi.org/10.21775/cimb.035.109

\begin{abstract}
The generation of new blood vessels from the existing vasculature is a dynamic and complex mechanism known as angiogenesis. Angiogenesis occurs during the entire lifespan of vertebrates and participates in many physiological processes. Furthermore, angiogenesis is also actively involved in many human diseases and disorders, including cancer, obesity and infections. Several inter-connected molecular pathways regulate angiogenesis, and post-translational modifications, such as phosphorylation, ubiquitination and SUMOylation, tightly regulate these mechanisms and play a key role in the control of the process. Here, we describe in detail the roles of ubiquitination and SUMOylation in the regulation of angiogenesis.
\end{abstract}

\section{Introduction}

The growth of new blood vessels from the existing vasculature is a process known as angiogenesis (Carmeliet, 2003; Ucuzian et al., 2010). In vertebrates, angiogenesis occurs across the entire lifespan and participates in multiple physiological processes, such as pregnancy, embryonic development and wound healing. Moreover, many diseases can promote de novo angiogenesis, a process also known as pathological angiogenesis or neoangiogenesis. In this regard, a well-known example is tumorigenesis-induced angiogenesis, during which hypoxic and starved cancer cells activate the molecular pathways involved in the formation of novel blood vessels, in order to supply nutrients and oxygen required for the tumour growth. Additionally, more than 70 different disorders have been associated to de novo angiogenesis including obesity, bacterial infections and AIDS (Carmeliet, 2003).

At the molecular level, angiogenesis relays on several pathways that cooperate in order to regulate in a precise spatial and temporal order the process. In this context, post-translational modifications (PTMs) play a central role in the regulation of these events, influencing the activation and stability of many growth factors, membrane receptors and downstream signalling effector molecules. Here, we will focus on the role of ubiquitination and SUMOylation in the regulation of angiogenesis.

\section{Molecular basics of angiogenesis}

Blood vessels arise from endothelial precursor cells, in a process known as vasculogenesis. Further stabilization of the new blood vessels, including their expansive growth and the formation of collateral bridges is known as angiogenesis (Carmeliet, 2003). During angiogenesis, a dynamic 
and complex crosstalk occurs between endothelial cells and the extracellular matrix in a tightly regulated manner in order to promote endothelial cells proliferation and differentiation, cytoskeletal reorganization and cell migration, and the formation of novel vessels (Carmeliet, 2003; Huang and Bao, 2004; Muñoz-Chápuli et al., 2004; Ucuzian et al., 2010). Endothelial cells, fibroblasts, platelets, inflammatory cells and cancer cells (Ucuzian et al., 2010) can all act as sources of angiogenic factors. Key pro-angiogenic factors are the Vascular Endothelial Growth Factors (VEGF1-5) and their receptors (VEGFR1, VEGFR2 and VEGFR3), the Placental Growth Factors (PlGFs), the Fibroblast Growth Factors (FGF1 and FGF2) and FGF receptors (FGFR1-4), the Transforming Growth Factor (TGF- $\beta$ ) family, the Tumour Necrosis Factor (TNF- $\alpha$ ), the family of the Angiopoietins (ANG1 and ANG2) and the TIE-1 and -2 receptors, Ephrins and Leptins (Carmeliet, 2003; Huang and Bao, 2004; Ucuzian et al., 2010). On the other hand, anti-angiogenic factors include the Thrombospondins (TSP1-4 and TSP-5/COMP), Angiostatins and Endostatins (Huang and Bao, 2004). Moreover, other players may differentially contribute to the control of angiogenesis, like the Matrix Metalloproteinases (MMPs), Integrins, and the extracellular matrix (ECM) (Kessenbrock et al., 2010). These factors activate several downstream signalling pathways. For example, VEGF, and similarly FGF, mainly activate the ERK/MAPK pathway (Larsson et al., 1999; Cross et al., 2000; Wu et al., 2000), leading to the transcription of master genes involved in cell proliferation, such as MYC, ELK-1, FOS, etc. (Muñoz-Chápuli et al., 2004). On the other end, VEGF can also act independently of the ERK/MAPK cascade by activating other pathways such as the STAT signalling (Muñoz-Chápuli et al., 2004). Interestingly, additional stimuli can cooperate with angiogenic factors. Accordingly, Nitric Oxide (NO) is able to potentiate the VEGFdependent activation of the angiogenic pathways (Donnini and Ziche, 2002). VEGF also directly controls the migration of endothelial cells during angiogenesis activating the RHO GTPases RHO and RAC, which are required for cell motility and the formation of focal adhesions (Soga et al., 2001a,b). Moreover, other factors, such as the Protein Kinase C (PKC) (Yamamura et al., 1996), or the receptor NOTCH (Hellström et al., 2007), can regulate cell migration in response to VEGF. On the other hand, anti-angiogenic factors such as the Endostatins are potent inhibitors of endothelial cells migration counteracting the formation of focal adhesions (Dixelius et al., 2003; Eriksson et al., 2003).

Typically, during endothelial cell migration, cell proliferation is enhanced, while apoptosis is repressed. Generally, the apoptotic signals that regulate angiogenesis and the fate of endothelial cells are mediated by TNF- $\alpha$ and TGF- $\beta$ signalling (Polunovsky et al., 1994; Choi and Ballermann, 1995). During angiogenesis, however, apoptotic pathways are inhibited by the crosstalk between Integrins, VEGF and FGF cascades that converge toward the activation of the AKT pathway (Gerber et al., 1998). Other signalling pathways involved in angiogenesis include WNT signalling (Dufourcq et al., 2002), and the pathways activated by cytokines, such as Pleiotrophin and Midkine (Stoica et al., 2001, 2002), and oestrogens (Hyder et al., 1996).

Because hypoxia is an important factor in angiogenesis, also Hypoxia-Inducible Factors (HIFs) play a fundamental role in neo-angiogenesis during tumour development (Pugh and Ratcliffe, 2003). HIF is a basic helix-loop-helix heterodimeric transcription factor that under hypoxic condition binds to hypoxic response elements (HREs) of the DNA inducing the transcription of a series of hypoxia-related genes, many of which are involved in angiogenesis (Semenza, 2000; Wenger, 2002). For example, VEGF transcription is directly upregulated by HIF activity in hypoxic conditions (Levy et al., 1998; Pugh and Ratcliffe, 2003; Zhang et al., 2012; De Francesco et al., 2013). Accordingly, Hif-1a knock out mice show abnormal vascular development and embryonic lethality (Maltepe et al., 1997; Kotch et al., 1999).

\section{PTMs in angiogenesis}

PTMs are a series of covalent modifications that occur following protein synthesis, and regulate protein activity, turnover and/or localization. The most common PTMs include phosphorylation, acetylation, glycosylation, ubiquitination and SUMOylation. Every PTM is strictly regulated by several molecular mechanisms and feedback loops. Interestingly, every single PTM described so far participates in the regulation and control 
of angiogenesis (Rahimi and Costello, 2015). In this review, we will focus on ubiquitination and SUMOylation, and will describe how these PTMs work and impact angiogenesis.

\section{Ubiquitination and SUMOylation in angiogenesis}

Ubiquitination and SUMOylation are PTMs that regulate the activity and fate of a plethora of proteins (Clague et al., 2015; Hendriks et al., 2015). Both ubiquitination and SUMOylation consist of the covalent binding of a small protein modifier (ubiquitin, $\mathrm{Ub}$ hereafter, or Small Ubiquitin-like Modifier, SUMO hereafter) to one or multiple lysine $(\mathrm{K})$ residues of a target protein. Both processes require three consecutive steps (Fig. 18.1), sequentially catalysed by E1, E2 and E3 ligases (Swatek and Komander, 2016; Rabellino et al., 2017). While for ubiquitination, a variety of E1-3 ligases are known, for SUMOylation, only one E1 (SAE1/2) and one E2 (UBC9) are known, and only few classes of E3 ligases have been described

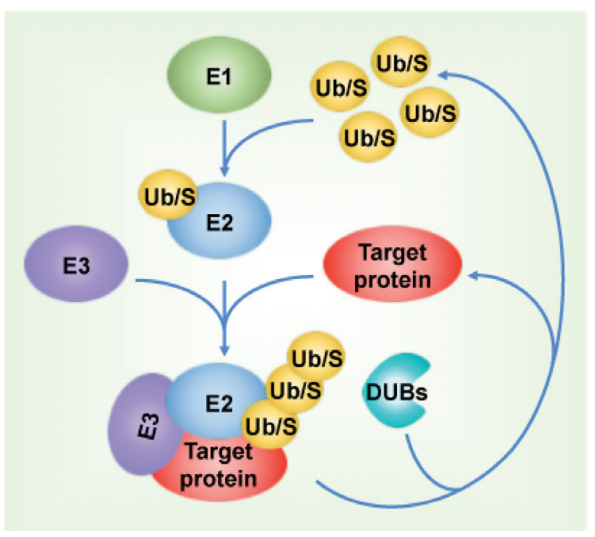

Figure 18.1 Ubiquitination and SUMOylation are reversible PTMs occurring through an E1, E2 and E3 enzymatic cascade. Ubiquitination and SUMOylation consist in the binding of either Ub or SUMO $(\mathrm{Ub} / \mathrm{S}$ in the figure) modifiers to a final target protein. This process occurs trough a sequential enzymatic cascade involving E1, E2 and E3 ligases. The last step of the reaction is usually facilitated by an E3 ligase that promotes the interaction between the E2 ligase and the target protein to be modified. Both ubiquitination and SUMOylation are reversible processes: specific de-ubiquitinase and de-SUMOylase enzymes (DUBs) remove Ub/SUMO from the target protein. so far, including RanBP2, PC2, TOPORS and the PIAS family (Rabellino et al., 2017).

Both ubiquitination and SUMOylation start with the attachment of a single $\mathrm{Ub}$ or SUMO to the target protein: these mono-ubiquitination/ SUMOylation events have several repercussions on the fate of the target. Moreover, both $\mathrm{Ub}$ and SUMO often form complex branched chains, and the complexity and/or the length of the chains will determine the fate of the modified-target. For example, $\mathrm{Ub}$ contains seven $\mathrm{K}$ residues that can be ubiquitinated, thus participating to the formation of complex and branched Ub chains (Kim et al., 2011; Wagner et al., 2011).

Owing to the presence of multiple SUMO paralogs, the SUMOylation machinery is more complex than ubiquitination. In vertebrates, five different SUMO genes exist and they encode for 5 different SUMO proteins (SUMO1-5): SUMO1, SUMO2 and SUMO3 are ubiquitously expressed, while SUMO4 and SUMO5 are tissue specific and not well characterized yet (Guo et al., 2004; Liang et al., 2016). In particular, SUMO 2 and SUMO3 are $97 \%$ alike, however, they share only 50\% homology with SUMO1 (Saitoh and Hinchey, 2000). Moreover, SUMO1 cannot be SUMOylated due to the lack of an internal acceptor $\mathrm{K}$. Therefore, SUMO1 is not able to form SUMO chains and it is considered a SUMO-chain terminator (Matic et al., 2008).

Both ubiquitination and SUMOylation are reversible modifications, and specific de-ubiquitination and de-SUMOylation enzymes (DUBs) are able to cleave Ub and SUMO from a modified protein (Wing, 2003; Yeh, 2009) (Fig. 18.1).

Although they share a very similar enzymatic cascade, ubiquitination and SUMOylation play different roles in several cellular processes. The main function of ubiquitination is to target proteins for their proteasome-dependent degradation (Swatek and Komander, 2016). However, depending on the size and the level of complexity of the Ub chain(s), the outcome can be different: some evidences indicate that multiple short- or branched-chains are more prone to induce protein degradation, while a single chain or a mono-ubiquitination tags can have a major role in intracellular signalling. Ubiquitination has been linked to DNA damage repair, transcriptional regulation, autophagy, activation of kinases and signalling, and regulation of the endosomal compartments during their internalization 
(Johnson, 2002; Sun and Chen, 2004; Grumati and Dikic, 2018). Similarly, SUMOylation has been associated to many important cellular functions, such as nuclear trafficking, DNA transcription, DNA damage repair, regulation of the cell cycle, and innate immunity (Flotho and Melchior, 2013).

Interestingly, ubiquitination and SUMOylation often cooperate. This is the case of DNA damage repair, where ubiquitination and SUMOylation tightly control the activity of the DNA damage repair machinery (Galanty et al., 2009; Morris et al., 2009). Alternatively, ubiquitination and SUMOylation cooperate to induce protein degradation, as in the case of PML and its oncogenic counterpart PML-RARA, where the SUMOylated PML is degraded after the specific ubiquitination of its SUMO chain (Lallemand-Breitenbach et al., 2008; Rabellino et al., 2012; Rabellino and Scaglioni, 2013). Finally, ubiquitination and SUMOylation can counteract each other's function, as for MYC, where its SUMOylation inhibits the interaction with the ubiquitination machinery (Rabellino et al., 2016).

\section{SUMO-1 and the regulation of endothelial cells}

SUMO proteins are evolutionary conserved across the whole eukaryotic kingdom and play important role in every aspect of cell physiology, including angiogenesis (Flotho and Melchior, 2013). It has been shown that SUMO1 expression in porcine aortic endothelial cells (PAECs) promotes cell proliferation, cell migration, and resistance to apoptosis, in a SUMO1-dose-dependent manner. Importantly, expression of SUMO1 improves the ability of the endothelial cells to form tubes and branching points, underlying its role in angiogenesis. Accordingly, similar observations were also obtained by studying the SUMO1 knock in mouse model, which exhibits a higher neo-vasculogenesis capacity than the control counterpart (Yang et al., 2013). Taken together, these data indicate that SUMO1 is directly involved in the regulation of endothelial cells during angiogenesis. It is worth noting that it has been established that SUMO2 and SUMO3 can compensate for SUMO1 functions (Evdokimov et al., 2008). Based on these observations it will be interesting to determine whether SUMO2/SUMO3 can compensate for the role of
SUMO1 in angiogenesis or whether SUMO1 is indispensable for this process.

\section{The regulation of VEGFR by ubiquitination and SUMOylation}

One of the most important factors involved in angiogenesis is VEGF and its associated receptors, VEGFRs. Particularly, VEGFR2 is a major key player in both physiological and pathological angiogenesis and it is massively regulated by PTMs, including phosphorylation, ubiquitination and SUMOylation. In particular, the binding of VEGF to VEGFR2 causes the activation of the receptor through multiple phosphorylation events, followed by its ubiquitination and internalization via clathrin-mediated/endosomal structures (Duval et al., 2003; Ewan et al., 2006; Bruns et al., 2010). It has been shown that VEGFR2 ubiquitination is required of its internalization, and once internalized, the receptor can be degraded through the lysosomes or can be recycled back to the plasma membrane (Bruns et al., 2010; Jopling et al., 2014). Interestingly, it has been recently reported that VEGFR2 can be ubiquitinated and degraded also in a VEGF-independent manner: in this case, the E1 ubiquitin-activating enzyme UBA1 controls the basal levels of VEGFR2 as well as its activity (Smith et al., 2017). These findings suggest that ubiquitination can independently regulate the availability of the VEGFR2 receptor during angiogenesis. Finally, the balance between the ubiquitinated and de-ubiquitinated status of VEGFR has also very important repercussions on endothelial cells during angiogenesis. Lately, it has been demonstrated the de-ubiquitinating enzyme USP8 plays a central role in the regulation of this balance. Accordingly, USP8 modulates the trafficking of VEGFR2 through the endosome and lysosome compartments regulating the degradation of the receptor (Smith et al., 2016).

Based on the studies summarized here, it is clear that ubiquitination plays a major role in the regulation of VEGFR signalling and trafficking in angiogenesis. Interestingly, a study using a knock out mouse model of the de-SUMOylase SENP1 has described that also SUMOylation regulates the intracellular trafficking of VEGFR (Zhou et al., 2018). In particular, it has been demonstrated that SENP1 protein levels increase in 
vascular endothelial cells in response to ischaemia. Further analyses have shown that SENP1 knock down in endothelial cells leads to an increase of the SUMOylation levels of VEGFR2, and to an impaired VEGFR2-dependent angiogenic signalling. Specifically, the SUMOylation of residue K1270 in VEGFR2 causes the receptor to accumulate in the Golgi compartment reducing its localization on the cell membrane (Zhou et al., 2018). Accordingly, analyses performed in diabetic mouse models, indicated that SENP1 expression was drastically reduced leading to an increase of VEGFR2 SUMOylation and inhibition of its signalling. All together, these data indicate that SUMOylation inhibits VEGFR2-dependent angiogenesis (Fig. 18.2), suggesting that the balance between the SUMOylated and non-SUMOylated VEGFR2 dictates its activation during angiogenesis (Zhou et al., 2018).

Interestingly, SUMOylation can also indirectly control VEGFR by regulating its gene expression. In this context, it has been reported that the master regulator of lymphangiogenesis PROX1 induces VEGFR expression in a SUMO-dependent manner (Pan et al., 2009). Based on these evidences, we conclude that during angiogenesis, SUMOylation can positively control the activity of VEGFR by regulating its spatial localization and/or its gene transcription. Further analyses are needed to identify the SUMO E3 ligases that control these processes.

\section{The regulation of NOTCH during angiogenesis by ubiquitination and SUMOylation}

NOTCH proteins (NOTCH1-4) are transmembrane receptors that operate in many cell types and at various stages during development. After the binding of one of their ligands, NOTCH undergoes a catalytic cleavage that releases its intracellular domain. At this point, the NOTCH intracellular domain (NOTCH-ICD) translocates into the nucleus where it forms an active transcriptional complex by interacting with CSL/RBP-J and MAML (Siebel and Lendahl, 2017) (Fig. 18.2). Extensive analyses of the NOTCH signalling have underlined its pivotal role in development and angiogenesis. Accordingly, $\mathrm{NOTCH}$ signalling regulates the transcription of a series of genes involved in angiogenesis, including VEGFR and Ephrins (Siekmann and Lawson, 2007; Kofler et al., 2011). These observations have been also validated in the Notch1-4 knock out mouse models, which exhibit severe defects in angiogenesis and vascular remodelling (Krebs et al., 2000).

Several PTMs regulates NOTCH signalling, including ubiquitination and SUMOylation. In particular, different ubiquitin E3 ligases have been associated to its degradation. However, it is not clear whether these ubiquitination processes directly impact or not on the angiogenic role of NOTCH (Lai, 2002). So far, the only ubiquitin E3 ligase that has been linked to the angiogenic activity of NOTCH is FBW7 (Tsunematsu et al., 2004) (Fig. 18.2). Accordingly, it has been shown that the $F b w 7$ knock out mouse model is embryonically lethal, and embryos die at early stage with massive abnormalities in the vascular development. Particularly, Fbw7 knock out embryos show an impaired vascular remodelling in the yolk sac and brain, with the ablation of major veins formation. Molecular analyses revealed that this phenotype is caused by Notch 4 accumulation in the embryos. The accumulation of Notch4 results in turn in the over-expression of Hey1, a transcriptional repressor directly regulated by Notch 4 and involved in vascular development and angiogenesis. Taken together, these data highlight the role of the ubiquitin ligase FBW7 in the positive regulation of angiogenesis, by directly regulating the Notch4-Hey1 signalling pathway (Tsunematsu et al., 2004).

Recently, it has also been shown that SUMOylation regulates angiogenesis by modulating NOTCH activity. For instance, in endothelial cells, the binding of the ligand DLL4 to NOTCH1 leads to VEGF transcriptional repression and to the inhibition of the VEGF signalling pathway (Fig. 18.2). This process impairs the angiogenic potential of endothelial cells (Benedito et al., 2009). Both in vitro and in vivo evidence has shown that inactivation of the de-SUMOylase SENP1 reduces cell motility, spheroid sprouting and capillary formation. This phenotype was associated to an increase of NOTCH1 activity, linking the function of SENP1 to NOTCH1 during angiogenesis. Noteworthy, the C-terminal domain of NOTCH-ICD contains several SUMO-binding motifs, and biochemical analyses confirmed that NOTCH-ICD 


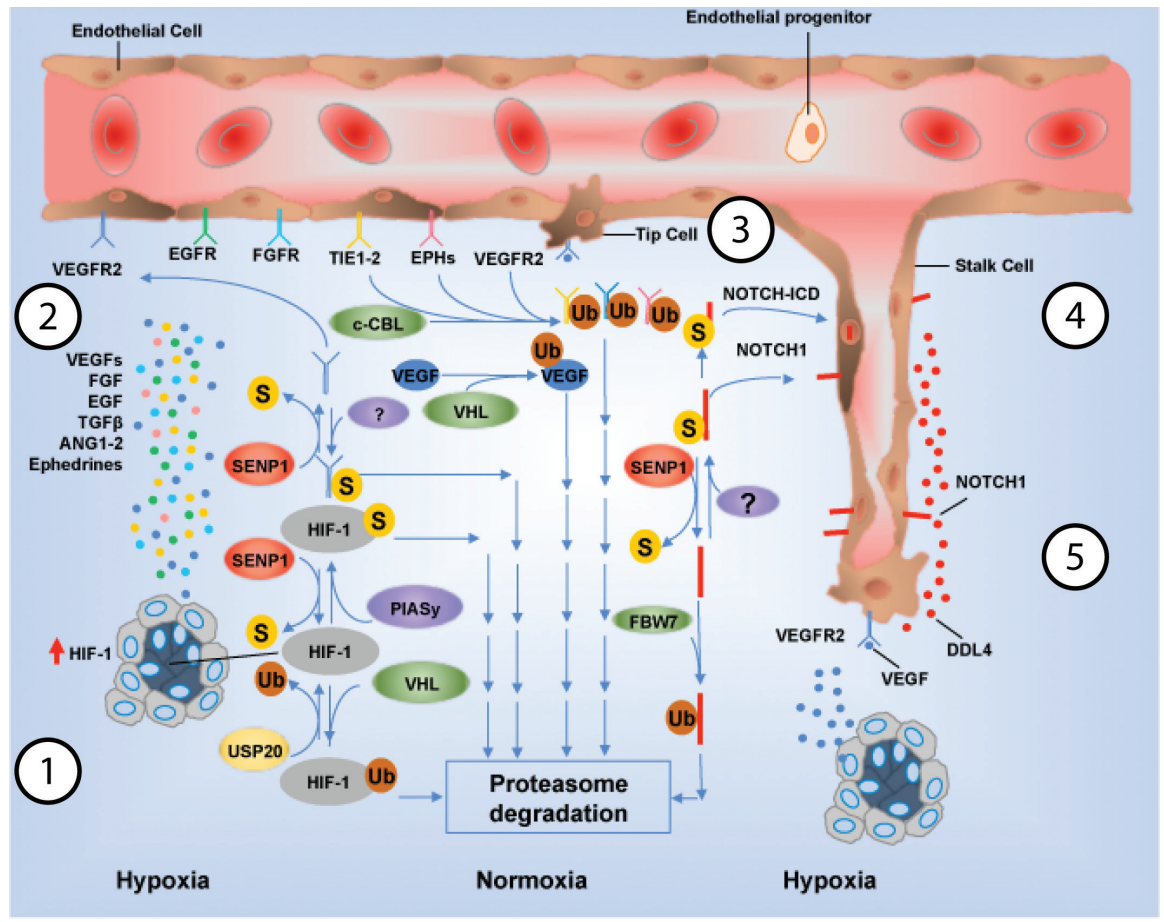

Figure 18.2 Ubiquitination and SUMOylation during angiogenesis. (1) Pro-angiogenic stimuli, such as a hypoxic environment, stimulate the expression of HIF-1 that in turn promotes the transcription of pro-angiogenic genes including VEGF. The level of HIF-1 depends on its ubiquitination/SUMOylation status: in normoxic or nonangiogenic conditions, the ubiquitin ligase VHL ubiquitinates HIF-1a directing it to proteasomal degradation. Moreover, SUMOylation PIASy-dependent leads to proteasome-dependent degradation of HIF-1a. On the other hand, both de-ubiquitination by ubiquitin-specific proteases (i.e. USP20) and de-SUMOylation by SENP1 are necessary to sustain HIF-1a stability and activity during angiogenesis. (2) HIF-1 leads to the transcription of genes encoding for pro-angiogenic factors such as VEGF, FGF, TGF- $\beta$, ANG1-2, and Ephedrines. These proangiogenic factors bind to the corresponding receptors exposed on the vascular endothelial cells (VEGFR2, FGFR, TIE1-2, EPHs). (3) The angiogenic factors gradient induces the migration of specialized endothelial cells (tip cells) that will begin the sprouting of new vessels. De-SUMOylation of VEGFR2 by SENP1 is required for angiogenesis, while SUMOylation of VEGFR2 promotes its degradation. However, the specific SUMO E3 ligase of VEGFR2 is still unknown. VEGFR, TIE1-2 and EPHs, are directed to degradation by c-CBL-dependent ubiquitination in non-angiogenic conditions. Under normoxic conditions also VEGF is targeted for degradation by VHL-dependent ubiquitination. (4) Endothelial progenitors differentiate into proliferative stalk cells that build up the main body of the new vessels. (5) To stop the process of sprouting and tube formation, VEGF induces the tip cells to secrete DLL4 ligand that will bind to NOTCH receptor on stalk cells. Activation of NOTCH, and its cleavage into NOTCH-ICD followed by its translocation into the nucleus, leads to VEGFR2 transcriptional repression thereby suppressing endothelial proliferation. SUMOylation of NOTCH1 is required for its cleavage into NOTCH-ICD contributing to the anti-angiogenic activity of NOTCH. While SENP1 is responsible for the deSUMOylation of $\mathrm{NOTCH}$, its specific SUMO E3 ligase has not been identified yet. Ubiquitination of NOTCH by FBW7 causes its inhibition and degradation.

is indeed SUMOylated on three residues (K2049, K2150 and K2252). Moreover, it has been shown that in endothelial cells, NOTCH-ICD exists predominately in its SUMOylated form and that SUMOylation of NOTCH1 is necessary for the cleavage and the formation of NOTCH-ICD upon DLL4 activation. Furthermore, SUMOylation increases NOTCH-ICD transcriptional activity and half-life, potentiating its anti-angiogenic signal. These data indicate that SUMOylation is a fundamental step for the positive regulation of NOTCH1 during angiogenesis. According to this hypothesis, SENP1 interacts with NOTCH1 and regulates its level of SUMOylation, modulating 
its anti-angiogenic activity (Zhu et al., 2017). Interestingly, the SUMO E3 ligase involved in the SUMOylation of NOTCH1 has not been identified yet and further analyses are needed in order to address this topic.

Noteworthy, SENP1 activity has also been directly correlated to erythropoiesis, where SENP1dependent de-SUMOylation of GATA1 is required during embryonic erythropoiesis (Yu et al., 2010).

\section{The VEGFR and NOTCH converging angiogenic signalling is regulated by ubiquitination}

Recent studies have demonstrated that the homeostasis between pro-angiogenic and anti-angiogenic signalling in endothelial cells is maintained by the balance between VEGFR and NOTCH signalling (Hellström et al., 2007; Lobov et al., 2007; Suchting et al., 2007; Benedito et al., 2009; Sakaue et al., 2017). In order to identify proteins involved in VEGFR activation that can also impact $\mathrm{NOTCH}$ signalling, human umbilical vein endothelial cells (HUVECs), a well-established cellular model used to study angiogenesis, were intensively screened in order to identify proteins that are up-regulated upon VEGFR activation but that can also impact $\mathrm{NOTCH}$ signalling. The findings revealed that when HUVEC cells are stimulated with VEGF, the zinc finger protein BAZF is up-regulated, leading to the induction of filopodia, cell elongation and the formation of a cellular network typical of angiogenesis. Accordingly, BAZF also negatively controls NOTCH signalling pathway, promoting VEGFdependent angiogenesis. Mechanistically, BAZF interacts with the $\mathrm{NOTCH}$ signalling factor $\mathrm{CBF} 1$ in a VEGFR-dependent way. Indeed, BAZF binding suppresses the transcriptional activity of CBF1 by releasing it from the promoters of the target genes. In addition, BAZF induces the ubiquitination of $\mathrm{CBF} 1$, targeting it for cytoplasmic translocation and proteasomal degradation. Further analyses showed that BAZF mediates the formation of a complex between $\mathrm{CBF} 1$ and the ubiquitin $\mathrm{E} 3$ ligase CUL3, with this effect being triggered by VEGFR activation. This finding indicates that VEGFdependent angiogenesis induces CUL3-dependent ubiquitination and degradation of CBF1 using BAZF as mediator. Accordingly, it has been shown that Bazf knock out mice suffer from angiogenic defects, up-regulation of the Notch signalling during development, and impaired wound healing during adulthood (Ohnuki et al., 2012).

Taken together, these data demonstrate that the ubiquitination machinery is able to regulate simultaneously pro- and anti-angiogenic factors in order to guarantee a fine-tuning of a complex mechanism such as angiogenesis.

\section{Hypoxia-induced angiogenesis}

Hypoxia-induced angiogenesis is a well-established hallmark of cancer (Hanahan and Weinberg, 2011). Accordingly, HIF-1, the master regulator of hypoxia, is up-regulated in several human cancers, and it associates with poor prognosis (Semenza, 2012). Interestingly, also HIF-1 is massively regulated by PTMs including ubiquitination and SUMOylation.

HIF-1 is a heterodimeric protein composed by the HIF- $1 \alpha$ and HIF- $1 \beta$ subunits. While HIF- $1 \beta$ is constitutively expressed, HIF- $1 \alpha$ is tightly regulated by oxygen availability. Under hypoxic conditions, HIF- $1 \alpha$ translocates from the cytosol to the nucleus where it interacts with HIF-1 $\beta$ promoting the transcription of hypoxic genes, including VEGFR (Eguchi et al., 1997). It has been established that, in normoxic conditions, HIF- $1 \alpha$ expression is usually kept at undetectable levels. Accordingly, oxygen induces HIF- $1 \alpha$ poly-ubiquitination and degradation by the ubiquitin E3 ligase complex PHD/ VHL/VBC (Masoud and Li, 2015) (Fig. 18.2). Even though other pathways contribute to regulate HIF-1 $\alpha$ stability (for example by regulating its mRNA levels or its translation), HIF-1 1 ubiquitindependent degradation represents the major control mechanism. The mechanism of HIF-1a regulation by the ubiquitination machinery has been extensively elucidated. Briefly, in normoxic conditions, the proline residues P402 and P564 of HIF-1 $\alpha$ are hydroxylated by the dioxygenases PHD1-3 in an oxygen-dependent way (Epstein et al., 2001; Ivan et al., 2001). In turn, this PTM activates the ubiquitination of HIF- $1 \alpha$ by VHL, leading to its proteasome-dependent degradation (Maxwell et al., 1999; Ohh et al., 2000; Tanimoto et al., 2000). Furthermore, HIF-1 1 levels can be regulated by mechanisms independent from the classic PHD/VHL machinery. For example, the chaperone protein HSP90 protects HIF- $1 \alpha$ from degradation. It has been shown that RACK1 mediates the dissociation of HSP90 from HIF- $1 \alpha$, which is in turn recognized by the ubiquitin ligase Elongin- $\mathrm{B} / \mathrm{C}$ and 
degraded (Liu et al., 2007). Alternatively, the kinase PLK3 regulates HIF-1 $\alpha$ levels during hypoxia by phosphorylating the serine residues S576 and S657 thereby inducing the degradation of HIF-1a (Xu et al., 2010a). Additionally, the transcription factor TAp3 is able to directly interact with HIF$1 a$, promoting the recruitment of the ubiquitin ligase MDM2, followed by its poly-ubiquitination and degradation in an oxygen-dependent manner (Amelio et al., 2015).

Since ubiquitination is largely involved in the control of HIF-1 $\alpha$ levels, de-ubiquitinating enzymes play an equally important role in maintaining the physiological level of HIF-1 $\alpha$. In this context, the de-ubiquitinating enzyme USP20 is able to interact with HIF- $1 \alpha$ and to regulate the transcription of downstream genes of HIF- $1 \alpha$ such as VEGF ( $\mathrm{Li}$ et al., 2005) (Fig. 18.2). Similarly, other de-ubiquitinating enzymes such as USP8 and UCHL1 were shown to modulate HIF-1 $1 \alpha$ levels and stability (Troilo et al., 2014; Goto et al., 2015).

Owing to the major role that HIF-1 plays in tumour-induced angiogenesis, the development of drugs able to promote its degradation has gained a lot of interest. In this scenario, the small molecules SCH66336 and Apigenin disrupt the interaction of HSP90 with HIF- $1 \alpha$, therefore inducing HIF-1 $\alpha$ degradation (Osada et al., 2004; Han et al., 2005; Melstrom et al., 2011). Moreover, other small molecules were found able to activate or increase the activity of the ubiquitin ligase complex. This is the case of the small molecule LW6, which increases the expression of VHL with a mechanism that has not been clarified yet (Lee et al., 2010).

Similar to ubiquitination, also SUMOylation has been suggested to regulate HIF- $1 \alpha$ levels, however, it is not clear whether SUMOylation increases or decreases HIF-1 $\alpha$ stability. HIF-1 $\alpha$ SUMOylation on the residues K391 and K477 was described for the first time in 2004, when it was proposed that the binding of SUMO1 to HIF-1 $\alpha$ promotes its stabilization and transcriptional activity (Bae et al., 2004). Similarly, the protein RSUME can SUMOylate HIF-1 $\alpha$, increasing its stability. RSUME is upregulated on hypoxic stress and promotes SUMO conjugation by interacting with UBC9 (CarbiaNagashima et al., 2007). Furthermore, the SUMO E3 ligase CBX4 increases hypoxia-induced VEGF expression and angiogenesis by SUMOylating HIF- $1 \alpha$ on the residues K391 and K477, increasing its transcriptional activity. These results were also corroborated by the observation that CBX4 expression positively correlates with the level of VEGF expression, angiogenesis and over-all survival in hepatocellular carcinoma patients (Li et al., 2014).

Despite these observations, other results indicated that the binding of SUMO1-3 to HIF- $1 \alpha$ negatively regulates its transcriptional activity without altering its half-life (Berta et al., 2007). A different and complex scenario has been reported about the effects of SENP1-dependent de-SUMOylation of HIF-1 $\alpha$. It has been shown that the de-SUMOylation of HIF-1 $\alpha$ by SENP1 inhibits the interaction between HIF- $1 \alpha$ and VHL, resulting in the stabilization of HIF-1 $\alpha$, therefore suggesting that HIF-1a SUMOylation promotes its degradation (Cheng et al., 2007). These data were confirmed by Senp1 knock out mice, which showed a lower induction of HIF-1 signalling (Xu et al., 2010b). Similarly, SENP1 stabilizes HIF-1 $\alpha$ levels and downstream signalling during myocardial ischaemia/reperfusion injury (Gu et al., 2014). Taken together, these results indicate that de-SUMOylation plays a pivotal role in maintaining HIF-1 $\alpha$ levels during angiogenesis and suggesting that SUMOylation might directly signal for the ubiquitination/degradation of HIF-1 $\alpha$. However, this evidence contradicts the hypothesis that SUMOylation is required for maintaining the stability of HIF-1 $\alpha$, and additional work is needed to solve these inconsistencies.

Whether PIAS family members contribute to regulate HIF-1 activity is also controversial. PIAS proteins (PIAS1-3 and PIASy) are SUMO E3 ligases involved in the regulation of several cellular functions, including angiogenesis, and they have been also associated to human malignancies (Rabellino et al., 2017). It has been reported that in hypoxic condition, PIASy interacts with HIF-1 $\alpha$ triggering its SUMOylation thereby promoting its degradation (Kang et al., 2010) (Fig. 18.2). Opposite results have been reported regarding the interaction of PIAS3 with HIF-1 $\alpha$. It has been shown that PIAS3 positively regulates HIF-1 $\alpha$ transcriptional activity, however, this function is independent of the SUMO E3 ligase activity of PIAS3 (Nakagawa et al., 2016). Taken together, these controversial observations suggest that different PIAS family members might have different roles in HIF-1 $\alpha$ regulation and activity. These 
controversies need to be addressed in more detail in the future.

\section{Role of the SUMO E3 ligase PIAS1 in angiogenesis}

The PIAS SUMO E3 ligases have been directly associated to angiogenesis independently of their ability to regulate HIF-1. In particular, the role of PIAS1 in angiogenesis has been recently characterized using the Pias 1 knock out mice model (Constanzo et al., 2016). It has been demonstrated that ablation of Pias1 in mice is embryonically lethal due to major defects in the vascular plexus of the yolk sac and thus in angiogenesis and erythropoiesis. Accordingly, Pias1 null mice embryos showed a significant reduction in blood vessel size and branching, which correlates with a low expression of the endothelial activation markers Angp2 and Vcam-1 (Constanzo et al., 2016). Interestingly, Vegfr levels were up-regulated in the yolk sac of Pias1 null mice suggesting a compensatory mechanism required for the activation of angiogenesis. These data were confirmed by in vitro experiments performed in HUVEC cells. Accordingly, expression of PIAS1 in this endothelial cellular model induces the expression of angiogenic markers and the down-regulation of anti-angiogenic genes, while PIAS1 knock down reduces the ability of HUVECs to form de novo tubes and branching structures (Constanzo et al., 2016). These data underline the role of PIAS 1 in regulating angiogenesis during embryogenesis, however it has not been described whether its function relies on its SUMO E3 ligase activity.

This issue was investigated by a recent work in which PIAS1 was described as the SUMO E3 ligase of MYC (Rabellino et al., 2016). The transcription factor MYC is a master transcription regulator involved in several cellular functions, including angiogenesis, and it is causally implicated in several human malignancies (Baudino et al., 2002; Dang, 2012). It has been described that the PIAS1dependent SUMOylation of MYC increases its half-life and its transcriptional activity. Accordingly, analyses of Pias1 null mice recapitulate the characteristics of the $M y c$ null mouse model, showing a developmentally delayed and hypoplastic yolk sac, lacking the characteristic microvillar structures of the vascular plexus (Rabellino et al., 2016). Taken together, these data strongly suggest that PIAS1 plays a fundamental role in angiogenesis, and this activity is likely due to its SUMO E3 ligase activity. Further studies will shed more light on the role of this SUMO ligase.

\section{PML in angiogenesis}

The promyelocytic leukaemia gene PML was described for the first time as product of the chromosomal translocation $\mathrm{t}(15 ; 17)(\mathrm{q} 24 ; \mathrm{q} 21)$ in acute promyelocytic leukaemia (APL) (Piazza et al., 2001). Soon, it became clear that PML is involved in the positive regulation of several tumour suppressive functions and other cellular processes, including angiogenesis (Salomoni and Pandolfi, 2002; Rabellino and Scaglioni, 2013). PML is massively regulated by several PTMs, including ubiquitination and SUMOylation, which influence its activity, functions and regulation, including the formation of the functional units of PML, known as PML Nuclear Bodies (PML-NBs) (Bernardi and Pandolfi, 2007; Rabellino and Scaglioni, 2013). It has been shown that PML negatively controls angiogenesis through the inhibition of HIF-1a translation by repressing mTOR activity (Bernardi et al., 2006). These findings elegantly described a new role of PML in controlling angiogenesis, however, whether PML ubiquitination or SUMOylation take part of this process is not clear.

In most recent years, however, a new layer of complexity regarding how PML regulates the mTOR/HIF-1 $\alpha$ pathway has been added. PML degradation is tightly regulated by a series of PTMs, including phosphorylation, SUMOylation and ubiquitination that occur in a precise spatial and temporal order (Scaglioni et al., 2006; Yuan et al., 2011; Rabellino and Scaglioni, 2013). It has been shown that under hypoxia conditions, the ubiquitin E3 ligase CUL3 substrate KLHL20 co-operates with CDK1/2 and with the isomerase PIN1 in order to induce PML ubiquitination and degradation in a HIF-1 dependent way. In this scenario, it has been also demonstrated that the KLHL20-dependent PML degradation promotes neo-angiogenesis (Yuan et al., 2011), pointing toward anti-angiogenic properties of PML. Furthermore, it has been shown that this mechanism is counteracted by SCP phosphatases, which de-phosphorylate PML blocking the KLHL20-dependent degradation, which in turn will inhibit HIF-1 signalling in a mTOR-dependent way (Lin et al., 2014). Interestingly, it has also been shown that PML-NBs are the site of the interaction 
between CUL3 and CBF1 during the regulation of the VEGF-dependent NOTCH signalling (Ohnuki et al., 2012), suggesting that PML and PML-NBs might regulate angiogenesis through several pathways and mechanisms. Despite the fact that SUMOylation has not been directly implicated in this process, based on the data available to date, we speculate that SUMOylation might be critical for the correct outcome of the process.

Finally, the role of PML in the inhibition of angiogenesis has been also demonstrated by its role in the positive-regulation of the anti-angiogenic factor Interferon- $\alpha$ (INF- $\alpha)$. Degradation of PML massively reduces the angiostatic effects of INF- $\alpha$. Interestingly, INF- $\alpha$ stimulation leads to the induction of PML, which in turn activates STAT1 and STAT2 anti-angiogenic activity by promoting STAT1/2 ISGylation (Hsu et al., 2017), an ubiquitin-like modification which functions and regulation are still largely unknown (VillarroyaBeltri et al., 2017).

\section{The regulation of TIE2 and FGFR by c-CBL ubiquitination}

The TIE2 receptor belongs to the family of the tyrosine kinase receptor (RTK) and is predominantly expressed on the surface of endothelial and hematopoietic cells (Dumont et al., 1992). The binding of TIE2 to its ligand ANG1 activates a downstream signalling cascade that positively regulates angiogenesis (Jones et al., 2001). Accordingly, Tie 2 null mice die at early embryonic stage due to the lack of the formation of the capillary plexus and severe heart defects (Dumont et al., 1994). It has been shown that ubiquitination regulates the turnover of TIE2 in a ligand-specific fashion. Indeed, the binding of ANG1 to TIE2 is sufficient to induce the activation of the receptor and its subsequent ubiquitination by the Ub E3 ligase c-CBL (Wehrle et al., 2009).

FGFR is another RTK that plays an essential role in angiogenesis (Yang et al., 2015). Similar to TIE2, ubiquitination regulates the turnover of FGFR and modulates its downstream signalling. Also, in this case, the ubiquitin E3 ligase involved in the ubiquitination of FGFR is c-CBL (Wong et al., 2002; Haugsten et al., 2008) (Fig. 18.2).

While these data indicate that ubiquitination of TIE2 and FGFR is necessary to regulate them during angiogenesis, it is not clear whether
SUMOylation may modulate the activity and the turnover of these receptors.

\section{Ubiquitination and de-ubiquitination of the WNT signalling in angiogenesis}

The WNT signalling pathways control a wide spectrum of cellular functions, including cell proliferation and migration. WNT pathways can be classified in canonical/ $\beta$-catenin-dependent and non-canonical pathways, and they both regulate and control angiogenesis. Accordingly, both in vitro and in vivo studies demonstrated that WNT and its Frizzled receptors regulate the migration of endothelial cells during angiogenesis (Zerlin et al., 2008). In the canonical pathway, WNT up-regulates the level of cytosolic $\beta$-catenin by inhibiting its ubiquitin-dependent degradation ( $\mathrm{Li}$ et al., 1999). The WNT-dependent accumulation of $\beta$-catenin promotes the nuclear translocation of $\beta$-catenin where it activates the transcription of genes involved in cell growth regulation and pro-angiogenic genes, such as VEGF and IL-8 (Tetsu and McCormick, 1999; You et al., 2002; MacDonald et al., 2009). Hence, the regulation of the $\beta$-catenin is critical, and ubiquitination plays a central role. It has been shown that c-CBL induces the ubiquitination of nuclear $\beta$-catenin thereby promoting its degradation, therefore negatively regulating angiogenesis. Interestingly, the re-localization of c-CBL from the cytoplasm to the nucleus it is induced by WNT (Chitalia et al., 2013), suggesting the activation of a feedback mechanism that controls this pathway. The re-localization of c-CBL is induced by the WNT-dependent phosphorylation of c-CBL on the tyrosine $\mathrm{Y} 731$, which promotes c-CBL dimerization, binding to the $\beta$-catenin and the nuclear re-localization (Shivanna et al., 2015).

Another ubiquitination-dependent regulation of the WNT signalling during angiogenesis has been described for the de-ubiquitinase Gumby. Noteworthy, the Gumby mouse mutants show severe angiogenic impairment during embryogenesis (Rivkin et al., 2013). Accordingly, Gumby knock out embryos die at early stage due to the insufficient development of the branching of the vascular system. It was previously reported that Gumby interacts with DVL2, which also plays an important role in WNT signalling (Rual et al., 2005). Further analyses performed in both in vitro and in vivo setting, indicated that Gumby negatively 
regulates WNT activity in endothelial cells, compromising their angiogenic potential (Rivkin et al., 2013).

Studies reported that SUMOylation of the co-repressors TBL1 and TBLR1 led to the activation of the WNT signalling in a $\beta$-catenin-dependent manner. Conversely, the SENP-1-dependent de-SUMOylation of TBL1 and TBLR1 inhibits this mechanism (Choi et al., 2011). Similarly, it has been demonstrated that the SUMO E3 ligase PIASy SUMOylates the WNT downstream effector TCF4, enhancing the $\beta$-catenin-dependent transcriptional activity of TCF4 (Yamamoto et al., 2003). These findings suggest that SUMOylation may play a role in the regulation of the WNT signalling, however, its role in this context has not been elucidated yet.

\section{Ephrins regulation during angiogenesis}

The binding of the membrane ligand Ephrins to their receptors initiates a series of downstream signalling that regulate the fate of endothelial cells during angiogenesis. Ephrins receptors are RTKs subdivided in two subclasses, EPHA and EPHB, activated by the ligands EphrinA and EphrinB, respectively. In vertebrates, a total of ten EPHA and six EPHB are expressed, and several in vitro and in vivo studies have underlined the role of $\mathrm{EPH}$ receptors and their ligands in the regulation of angiogenesis (Pasquale, 2005). Because Ephrin ligands are anchored to the cell membrane, the interaction with their receptors requires a cellto-cell interaction. Once the activated receptor induces downstream signalling cascade, the stimulus is extinguished through a process that includes the receptor internalization and its degradation via ubiquitination (Litterst et al., 2007). Similar to other RTKs involved in angiogenesis, it has been shown that c-CBL is the ubiquitin E3 ligase responsible for EPHB receptor ubiquitination (Fasen et al., 2008) (Fig. 18.2). To date, however, there are no evidences that SUMOylation is involved in the regulation of Ephrins.

\section{The role of extracellular Ub in the regulation of angiogenesis}

Extracellular Ub regulates immune responses during inflammation, organ injuries and fibrosis, and elevated plasma levels of Ub correlate with several human pathologies (Asseman et al.,
1994; Takagi et al., 1999; Majetschak et al., 2005; Sujashvili, 2016). It has been also shown that the extracellular Ub promotes angiogenesis. Accordingly, using cardiac micro-vascular endothelial cells (CMECs), which is the major cell type involved in cardiac angiogenesis, it has been demonstrated that extracellular $\mathrm{Ub}$ promotes the expression of VEGFR, thereby triggering cytoskeletal rearrangement, cell migration and tube formation (Steagall et al., 2014). These observations raise several questions regarding the molecular mechanisms by which extracellular $\mathrm{Ub}$ activates angiogenesis. Such aspects should be of potential interest in view of future therapeutic applications of this discovery.

\section{Conclusions and remarks}

Ubiquitination and SUMOylation are PTMs that play fundamental roles in every aspect of human physiology. Here we have summarized their major roles in angiogenesis known so far. Because of the extreme significance of angiogenesis in tumour development and in other human diseases, both ubiquitination and SUMOylation might represent valuable candidate targets for the generation of new, more effective drugs for the treatment of these pathologies.

In particular, even though SUMOylation has being known for more than two decades (GeissFriedlander and Melchior, 2007), it is still a fairly unknown process, and its involvement in angiogenesis regulation remains largely uncharacterized. More efforts should be made in order to shed light on this important PTM and its contribution to angiogenesis.

\section{References}

Amelio, I., Inoue, S., Markert, E.K., Levine, A.J., Knight, R.A., Mak, T.W., and Melino, G. (2015). TAp73 opposes tumor angiogenesis by promoting hypoxia-inducible factor $1 \alpha$ degradation. Proc. Natl. Acad. Sci. U.S.A. 112, 226-231. https://doi.org/10.1073/pnas.1410609111.

Asseman, C., Pancré, V., Delanoye, A., Capron, A., and Auriault, C. (1994). A radioimmunoassay for the quantification of human ubiquitin in biological fluids: application to parasitic and allergic diseases. J. Immunol. Methods 173, 93-101.

Bae, S.H., Jeong, J.W., Park, J.A., Kim, S.H., Bae, M.K., Choi, S.J., and Kim, K.W. (2004). Sumoylation increases HIFlalpha stability and its transcriptional activity. Biochem. Biophys. Res. Commun. 324, 394-400.

Baudino, T.A., McKay, C., Pendeville-Samain, H., Nilsson, J.A., Maclean, K.H., White, E.L., Davis, A.C., Ihle, J.N., and Cleveland, J.L. (2002). c-Myc is essential for 
vasculogenesis and angiogenesis during development and tumor progression. Genes Dev. 16, 2530-2543. https://doi.org/10.1101/gad.1024602.

Benedito, R., Roca, C., Sörensen, I., Adams, S., Gossler, A., Fruttiger, M., and Adams, R.H. (2009). The notch ligands Dll4 and Jagged1 have opposing effects on angiogenesis. Cell 137, 1124-1135. https://doi. org/10.1016/j.cell.2009.03.025.

Bernardi, R., and Pandolfi, P.P. (2007). Structure, dynamics and functions of promyelocytic leukaemia nuclear bodies. Nat. Rev. Mol. Cell Biol. 8, 1006-1016.

Bernardi, R., Guernah, I., Jin, D., Grisendi, S., Alimonti, A., Teruya-Feldstein, J., Cordon-Cardo, C., Simon, M.C., Rafii, S., and Pandolfi, P.P. (2006). PML inhibits HIF-1alpha translation and neoangiogenesis through repression of mTOR. Nature 442, 779-785.

Berta, M.A., Mazure, N., Hattab, M., Pouysségur, J., and Brahimi-Horn, M.C. (2007). SUMOylation of hypoxiainducible factor-1alpha reduces its transcriptional activity. Biochem. Biophys. Res. Commun. 360, 646-652.

Bruns, A.F., Herbert, S.P., Odell, A.F., Jopling, H.M., Hooper, N.M., Zachary, I.C., Walker, J.H., and Ponnambalam, S. (2010). Ligand-stimulated VEGFR2 signaling is regulated by co-ordinated trafficking and proteolysis. Traffic 11, 161-174. https://doi.org/10.1111/j.16000854.2009.01001.x.

Carbia-Nagashima, A., Gerez, J., Perez-Castro, C., PaezPereda, M., Silberstein, S., Stalla, G.K., Holsboer, F., and Arzt, E. (2007). RSUME, a small RWD-containing protein, enhances SUMO conjugation and stabilizes HIF-1alpha during hypoxia. Cell 131, 309-323.

Carmeliet, P. (2003). Angiogenesis in health and disease. Nat. Med. 9, 653-660. https://doi.org/10.1038/ nm0603-653.

Cheng, J., Kang, X., Zhang, S., and Yeh, E.T. (2007). SUMO-specific protease 1 is essential for stabilization of HIF 1alpha during hypoxia. Cell 131, 584-595.

Chitalia, V., Shivanna, S., Martorell, J., Meyer, R., Edelman, E., and Rahimi, N. (2013). c-Cbl, a ubiquitin E3 ligase that targets active $\beta$-catenin: a novel layer of Wnt signaling regulation. J. Biol. Chem. 288, 23505-23517. https://doi.org/10.1074/jbc.M113.473801.

Choi, H.K., Choi, K.C., Yoo, J.Y., Song, M., Ko, S.J., Kim, C.H., Ahn, J.H., Chun, K.H., Yook, J.I., and Yoon, H.G. (2011). Reversible SUMOylation of TBL1TBLR1 regulates $\beta$-catenin-mediated Wnt signaling. Mol. Cell 43, 203-216. https://doi.org/10.1016/j. molcel.2011.05.027.

Choi, M.E., and Ballermann, B.J. (1995). Inhibition of capillary morphogenesis and associated apoptosis by dominant negative mutant transforming growth factorbeta receptors. J. Biol. Chem. 270, 21144-21150.

Clague, M.J., Heride, C., and Urbé, S. (2015). The demographics of the ubiquitin system. Trends Cell Biol. 25, 417-426. https://doi.org/10.1016/j. tcb.2015.03.002.

Constanzo, J.D., Deng, M., Rindhe, S., Tang, K.J., Zhang, C.C., and Scaglioni, P.P. (2016). Pias1 is essential for erythroid and vascular development in the mouse embryo. Dev. Biol. 415, 98-110.

Cross, M.J., Hodgkin, M.N., Roberts, S., Landgren, E., Wakelam, M.J., and Claesson-Welsh, L. (2000). Tyrosine
766 in the fibroblast growth factor receptor- 1 is required for FGF-stimulation of phospholipase C, phospholipase $\mathrm{D}$, phospholipase $\mathrm{A}(2)$, phosphoinositide 3-kinase and cytoskeletal reorganisation in porcine aortic endothelial cells. J. Cell. Sci. 113, 643-651.

Dang, C.V. (2012). MYC on the path to cancer. Cell 149, 22-35. https://doi.org/10.1016/j.cell.2012.03.003.

De Francesco, E.M., Lappano, R., Santolla, M.F., Marsico, S., Caruso, A., and Maggiolini, M. (2013). HIF-1a/GPER signaling mediates the expression of VEGF induced by hypoxia in breast cancer associated fibroblasts (CAFs). Breast Cancer Res. 15, R64.

Dixelius, J., Cross, M.J., Matsumoto, T., and ClaessonWelsh, L. (2003). Endostatin action and intracellular signaling: beta-catenin as a potential target? Cancer Lett. 196, 1-12.

Donnini, S., and Ziche, M. (2002). Constitutive and inducible nitric oxide synthase: role in angiogenesis. Antioxid. Redox Signal. 4, 817-823. https://doi. org/10.1089/152308602760598972.

Dufourcq, P., Couffinhal, T., Ezan, J., Barandon, L., Moreau, C., Daret, D., and Duplàa, C. (2002). FrzA, a secreted frizzled related protein, induced angiogenic response. Circulation 106, 3097-3103.

Dumont, D.J., Yamaguchi, T.P., Conlon, R.A., Rossant, J., and Breitman, M.L. (1992). tek, a novel tyrosine kinase gene located on mouse chromosome 4, is expressed in endothelial cells and their presumptive precursors. Oncogene 7, 1471-1480.

Dumont, D.J., Gradwohl, G., Fong, G.H., Puri, M.C., Gertsenstein, M., Auerbach, A., and Breitman, M.L. (1994). Dominant-negative and targeted null mutations in the endothelial receptor tyrosine kinase, tek, reveal a critical role in vasculogenesis of the embryo. Genes Dev. 8, 1897-1909.

Duval, M., Bédard-Goulet, S., Delisle, C., and Gratton, J.P. (2003). Vascular endothelial growth factor-dependent down-regulation of Flk-1/KDR involves Cbl-mediated ubiquitination. Consequences on nitric oxide production from endothelial cells. J. Biol. Chem. 278, 20091-20097. https://doi.org/10.1074/jbc.M301410200.

Eguchi, H., Ikuta, T., Tachibana, T., Yoneda, Y., and Kawajiri, K. (1997). A nuclear localization signal of human aryl hydrocarbon receptor nuclear translocator/ hypoxia-inducible factor lbeta is a novel bipartite type recognized by the two components of nuclear poretargeting complex. J. Biol. Chem. 272, 17640-17647.

Epstein, A.C., Gleadle, J.M., McNeill, L.A., Hewitson, K.S., O’Rourke, J., Mole, D.R., Mukherji, M., Metzen, E., Wilson, M.I., Dhanda, A., et al. (2001). C. elegans EGL-9 and mammalian homologs define a family of dioxygenases that regulate HIF by prolyl hydroxylation. Cell 107, 43-54.

Eriksson, K., Magnusson, P., Dixelius, J., Claesson-Welsh, L., and Cross, M.J. (2003). Angiostatin and endostatin inhibit endothelial cell migration in response to FGF and VEGF without interfering with specific intracellular signal transduction pathways. FEBS Lett. 536, 19-24.

Evdokimov, E., Sharma, P., Lockett, S.J., Lualdi, M., and Kuehn, M.R. (2008). Loss of SUMO1 in mice affects RanGAP1 localization and formation of PML nuclear bodies, but is not lethal as it can be compensated by SUMO2 or SUMO3. J. Cell Sci. 121, 4106-4113. 
Ewan, L.C., Jopling, H.M., Jia, H., Mittar, S., Bagherzadeh, A., Howell, G.J., Walker, J.H., Zachary, I.C., and Ponnambalam, S. (2006). Intrinsic tyrosine kinase activity is required for vascular endothelial growth factor receptor 2 ubiquitination, sorting and degradation in endothelial cells. Traffic 7, 1270-1282.

Fasen, K., Cerretti, D.P., and Huynh-Do, U. (2008). Ligand binding induces Cbl-dependent EphB1 receptor degradation through the lysosomal pathway. Traffic 9, 251-266.

Flotho, A., and Melchior, F. (2013). Sumoylation: a regulatory protein modification in health and disease. Annu. Rev. Biochem. 82, 357-385. https://doi. org/10.1146/annurev-biochem-061909-093311.

Galanty, Y., Belotserkovskaya, R., Coates, J., Polo, S., Miller, K.M., and Jackson, S.P. (2009). Mammalian SUMO E3-ligases PIAS1 and PIAS4 promote responses to DNA double-strand breaks. Nature 462, 935-939. https://doi.org/10.1038/nature08657.

Geiss-Friedlander, R., and Melchior, F. (2007). Concepts in sumoylation: a decade on. Nat. Rev. Mol. Cell Biol. 8, 947-956.

Gerber, H.P., McMurtrey, A., Kowalski, J., Yan, M., Keyt, B.A., Dixit, V., and Ferrara, N. (1998). Vascular endothelial growth factor regulates endothelial cell survival through the phosphatidylinositol 3'-kinase/Akt signal transduction pathway. Requirement for Flk-1/ KDR activation. J. Biol. Chem. 273, 30336-30343.

Goto, Y., Zeng, L., Yeom, C.J., Zhu, Y., Morinibu, A., Shinomiya, K., Kobayashi, M., Hirota, K., Itasaka, S., Yoshimura, M., et al. (2015). UCHL1 provides diagnostic and antimetastatic strategies due to its deubiquitinating effect on HIF-1 $\alpha$. Nat. Commun. 6, 6153. https://doi.org/10.1038/ncomms7153.

Grumati, P., and Dikic, I. (2018). Ubiquitin signaling and autophagy. J. Biol. Chem. 293, 5404-5413. https://doi. org/10.1074/jbc.TM117.000117.

Gu, J., Fan, Y., Liu, X., Zhou, L., Cheng, J., Cai, R., and Xue, S. (2014). SENP1 protects against myocardial ischaemia/ reperfusion injury via a HIF1 $\alpha$-dependent pathway. Cardiovasc. Res. 104, 83-92. https://doi.org/10.1093/ $\mathrm{cvr} / \mathrm{cvu} 177$.

Guo, D., Li, M., Zhang, Y., Yang, P., Eckenrode, S., Hopkins, D., Zheng, W., Purohit, S., Podolsky, R.H., Muir, A., et al. (2004). A functional variant of SUMO4, a new I kappa $\mathrm{B}$ alpha modifier, is associated with type 1 diabetes. Nat. Genet. 36, 837-841. https://doi.org/10.1038/ng1391.

Han, J.Y., Oh, S.H., Morgillo, F., Myers, J.N., Kim, E., Hong, W.K., and Lee, H.Y. (2005). Hypoxia-inducible factor lalpha and antiangiogenic activity of farnesyltransferase inhibitor SCH66336 in human aerodigestive tract cancer. J. Natl. Cancer Inst. 97, 1272-1286.

Hanahan, D., and Weinberg, R.A. (2011). Hallmarks of cancer: the next generation. Cell 144, 646-674. https:// doi.org/10.1016/j.cell.2011.02.013.

Haugsten, E.M., Malecki, J., Bjørklund, S.M., Olsnes, S., and Wesche, J. (2008). Ubiquitination of fibroblast growth factor receptor 1 is required for its intracellular sorting but not for its endocytosis. Mol. Biol. Cell 19, 33903403. https://doi.org/10.1091/mbc.E07-12-1219.

Hellström, M., Phng, L.K., Hofmann, J.J., Wallgard, E., Coultas, L., Lindblom, P., Alva, J., Nilsson, A.K., Karlsson, L., Gaiano, N., et al. (2007). Dll4 signalling through Notch1 regulates formation of tip cells during angiogenesis. Nature 445, 776-780.

Hendriks, I.A., D’Souza, R.C., Chang, J.G., Mann, M., and Vertegaal, A.C. (2015). System-wide identification of wild-type SUMO-2 conjugation sites. Nat. Commun. 6, 7289. https://doi.org/10.1038/ncomms8289.

Hsu, K.S., Zhao, X., Cheng, X., Guan, D., Mahabeleshwar, G.H., Liu, Y., Borden, E., Jain, M.K., and Kao, H.Y. (2017). Dual regulation of Stat 1 and Stat 3 by the tumor suppressor protein PML contributes to interferon $\alpha$-mediated inhibition of angiogenesis. J. Biol. Chem. 292, 10048-10060. https://doi.org/10.1074/jbc. M116.771071.

Huang, Z., and Bao, S.D. (2004). Roles of main pro- and anti-angiogenic factors in tumor angiogenesis. World J. Gastroenterol. 10, 463-470.

Hyder, S.M., Stancel, G.M., Chiappetta, C., Murthy, L., Boettger-Tong, H.L., and Makela, S. (1996). Uterine expression of vascular endothelial growth factor is increased by estradiol and tamoxifen. Cancer Res. 56, 3954-3960.

Ivan, M., Kondo, K., Yang, H., Kim, W., Valiando, J., Ohh, M., Salic, A., Asara, J.M., Lane, W.S., and Kaelin, W.G. (2001). HIFalpha targeted for VHL-mediated destruction by proline hydroxylation: implications for O2 sensing. Science 292, 464-468. https://doi. org/10.1126/science.1059817.

Johnson, E.S. (2002). Ubiquitin branches out. Nat. Cell Biol. 4, E295-8. https://doi.org/10.1038/ncb1202-e295.

Jones, N., Iljin, K., Dumont, D.J., and Alitalo, K. (2001). Tie receptors: new modulators of angiogenic and lymphangiogenic responses. Nat. Rev. Mol. Cell Biol. 2, 257-267. https://doi.org/10.1038/35067005.

Jopling, H.M., Odell, A.F., Pellet-Many, C., Latham, A.M., Frankel, P., Sivaprasadarao, A., Walker, J.H., Zachary, I.C., and Ponnambalam, S. (2014). Endosome-to-plasma membrane recycling of VEGFR2 receptor tyrosine kinase regulates endothelial function and blood vessel formation. Cells 3, 363-385. https://doi.org/10.3390/ cells3020363.

Kang, X., Li, J., Zou, Y., Yi, J., Zhang, H., Cao, M., Yeh, E.T., and Cheng, J. (2010). PIASy stimulates HIF1a SUMOylation and negatively regulates HIF $1 \alpha$ activity in response to hypoxia. Oncogene 29, 5568-5578. https://doi.org/10.1038/onc.2010.297.

Kessenbrock, K., Plaks, V., and Werb, Z. (2010). Matrix metalloproteinases: regulators of the tumor microenvironment. Cell 141, 52-67. https://doi. org/10.1016/j.cell.2010.03.015.

Kim, W., Bennett, E.J., Huttlin, E.L., Guo, A., Li, J., Possemato, A., Sowa, M.E., Rad, R., Rush, J., Comb, M.J., et al. (2011). Systematic and quantitative assessment of the ubiquitin-modified proteome. Mol. Cell 44, 325 340. https://doi.org/10.1016/j.molcel.2011.08.025.

Kofler, N.M., Shawber, C.J., Kangsamaksin, T., Reed, H.O., Galatioto, J., and Kitajewski, J. (2011). Notch signaling in developmental and tumor angiogenesis. Genes Cancer 2, 1106-1116. https://doi. org $/ 10.1177 / 1947601911423030$.

Kotch, L.E., Iyer, N.V., Laughner, E., and Semenza, G.L. (1999). Defective vascularization of HIF-1alpha-null embryos is not associated with VEGF deficiency but with mesenchymal cell death. Dev. Biol. 209, 254-267. 
Krebs, L.T., Xue, Y., Norton, C.R., Shutter, J.R., Maguire, M., Sundberg, J.P., Gallahan, D., Closson, V., Kitajewski, J., Callahan, R., et al. (2000). Notch signaling is essential for vascular morphogenesis in mice. Genes Dev. 14, 1343-1352.

Lai, E.C. (2002). Protein degradation: four E3s for the notch pathway. Curr. Biol. 12, R74-8.

Lallemand-Breitenbach, V., Jeanne, M., Benhenda, S., Nasr, R., Lei, M., Peres, L., Zhou, J., Zhu, J., Raught, B., and de Thé, H. (2008). Arsenic degrades PML or PMLRARalpha through a SUMO-triggered RNF4/ubiquitinmediated pathway. Nat. Cell Biol. 10, 547-555. https:// doi.org/10.1038/ncb1717.

Larsson, H., Klint, P., Landgren, E., and Claesson-Welsh, L. (1999). Fibroblast growth factor receptor-1-mediated endothelial cell proliferation is dependent on the Src homology ( $\mathrm{SH}$ ) 2/SH3 domain-containing adaptor protein Crk. J. Biol. Chem. 274, 25726-25734.

Lee, K., Kang, J.E., Park, S.K., Jin, Y., Chung, K.S., Kim, H.M., Lee, K., Kang, M.R., Lee, M.K., Song, K.B., et al. (2010). LW6, a novel HIF-1 inhibitor, promotes proteasomal degradation of HIF-1alpha via upregulation of VHL in a colon cancer cell line. Biochem. Pharmacol. 80, 982-989. https://doi.org/10.1016/j.bcp.2010.06.018.

Levy, N.S., Chung, S., Furneaux, H., and Levy, A.P. (1998). Hypoxic stabilization of vascular endothelial growth factor mRNA by the RNA-binding protein HuR. J. Biol. Chem. 273, 6417-6423.

Li, J., Xu, Y., Long, X.D., Wang, W., Jiao, H.K., Mei, Z., Yin, Q.Q. Ma, L.N., Zhou, A.W., Wang, L.S., et al. (2014). Cbx4 governs HIF-1a to potentiate angiogenesis of hepatocellular carcinoma by its SUMO E3 ligase activity. Cancer Cell 25, 118-131. https://doi.org/10.1016/j. ccr.2013.12.008.

Li, L., Yuan, H., Weaver, C.D., Mao, J., Farr, G.H., Sussman, D.J., Jonkers, J., Kimelman, D., and Wu, D. (1999). Axin and Fratl interact with dvl and GSK, bridging Dvl to GSK in Wnt-mediated regulation of LEF-1. EMBO J. 18, 4233-4240. https://doi.org/10.1093/ emboj/18.15.4233.

Li, Z., Wang, D., Messing, E.M., and Wu, G. (2005). VHL protein-interacting deubiquitinating enzyme 2 deubiquitinates and stabilizes HIF-1alpha. EMBO Rep. 6, 373-378.

Liang, Y.C., Lee, C.C., Yao, Y.L., Lai, C.C., Schmitz, M.L., and Yang, W.M. (2016). SUMO5, a Novel Poly-SUMO Isoform, Regulates PML Nuclear Bodies. Sci. Rep. 6, 26509. https://doi.org/10.1038/srep26509.

Lin, Y.C., Lu, L.T., Chen, H.Y., Duan, X., Lin, X., Feng, X.H., Tang, M.J., and Chen, R.H. (2014). SCP phosphatases suppress renal cell carcinoma by stabilizing PML and inhibiting mTOR/HIF signaling. Cancer Res. 74, 6935-6946. https://doi.org/10.1158/0008-5472. CAN-14-1330.

Litterst, C., Georgakopoulos, A., Shioi, J., Ghersi, E., Wisniewski, T., Wang, R., Ludwig, A., and Robakis, N.K. (2007). Ligand binding and calcium influx induce distinct ectodomain/gamma-secretase-processing pathways of EphB2 receptor. J. Biol. Chem. 282, 1615516163.

Liu, Y.V., Baek, J.H., Zhang, H., Diez, R., Cole, R.N., and Semenza, G.L. (2007). RACK1 competes with HSP90 for binding to HIF-1alpha and is required for
$\mathrm{O}(2)$-independent and HSP90 inhibitor-induced degradation of HIF-1 alpha. Mol. Cell 25, 207-217.

Lobov, I.B., Renard, R.A., Papadopoulos, N., Gale, N.W., Thurston, G., Yancopoulos, G.D., and Wiegand, S.J. (2007). Delta-like ligand 4 (Dll4) is induced by VEGF as a negative regulator of angiogenic sprouting. Proc. Natl. Acad. Sci. U.S.A. 104, 3219-3224.

MacDonald, B.T., Tamai, K., and He, X. (2009). Wnt/ beta-catenin signaling: components, mechanisms, and diseases. Dev. Cell 17, 9-26. https://doi.org/10.1016/j. devcel.2009.06.016.

Majetschak, M., King, D.R., Krehmeier, U., Busby, L.T., Thome, C., Vajkoczy, S., and Proctor, K.G. (2005). Ubiquitin immunoreactivity in cerebrospinal fluid after traumatic brain injury: clinical and experimental findings. Crit. Care Med. 33, 1589-1594.

Maltepe, E., Schmidt, J.V., Baunoch, D., Bradfield, C.A., and Simon, M.C. (1997). Abnormal angiogenesis and responses to glucose and oxygen deprivation in mice lacking the protein ARNT. Nature 386, 403-407. https://doi.org/10.1038/386403a0.

Masoud, G.N., and Li, W. (2015). HIF-1 $\alpha$ pathway: role, regulation and intervention for cancer therapy. Acta Pharm. Sin. B 5, 378-389. https://doi.org/10.1016/j. apsb.2015.05.007.

Matic, I., van Hagen, M., Schimmel, J., Macek, B., Ogg, S.C., Tatham, M.H., Hay, R.T., Lamond, A.I., Mann, M., and Vertegaal, A.C.O. (2008). In vivo identification of human small ubiquitin-like modifier polymerization sites by high accuracy mass spectrometry and an in vitro to in vivo strategy. Mol. Cell Proteomics 7, 132-144. https://doi.org/10.1074/mcp.M700173-MCP200.

Maxwell, P.H., Wiesener, M.S., Chang, G.W., Clifford, S.C., Vaux, E.C., Cockman, M.E., Wykoff, C.C., Pugh, C.W., Maher, E.R., and Ratcliffe, P.J. (1999). The tumour suppressor protein VHL targets hypoxia-inducible factors for oxygen-dependent proteolysis. Nature 399, 271-275. https://doi.org/10.1038/20459.

Melstrom, L.G., Salabat, M.R., Ding, X.Z., Strouch, M.J., Grippo, P.J., Mirzoeva, S., Pelling, J.C., and Bentrem, D.J. (2011). Apigenin down-regulates the hypoxia response genes: HIF-1 $\alpha$, GLUT-1, and VEGF in human pancreatic cancer cells. J. Surg. Res. 167, 173-181. https://doi.org/10.1016/j.jss.2010.10.041.

Morris, J.R., Boutell, C., Keppler, M., Densham, R., Weekes, D., Alamshah, A., Butler, L., Galanty, Y., Pangon, L., Kiuchi, T., et al. (2009). The SUMO modification pathway is involved in the BRCA1 response to genotoxic stress. Nature 462, 886-890. https://doi.org/10.1038/ nature 08593 .

Muñoz-Chápuli, R., Quesada, A.R., and Angel Medina, M. (2004). Angiogenesis and signal transduction in endothelial cells. Cell. Mol. Life Sci. 61, 2224-2243. https://doi.org/10.1007/s00018-004-4070-7.

Nakagawa, K., Kohara, T., Uehata, Y., Miyakawa, Y., Sato-Ueshima, M., Okubo, N., Asaka, M., Takeda, H., and Kobayashi, M. (2016). PIAS3 enhances the transcriptional activity of HIF-1 $\alpha$ by increasing its protein stability. Biochem. Biophys. Res. Commun. 469, 470-476. https://doi.org/10.1016/j.bbrc.2015.12.047.

Ohh, M., Park, C.W., Ivan, M., Hoffman, M.A., Kim, T.Y., Huang, L.E., Pavletich, N., Chau, V., and Kaelin, W.G. (2000). Ubiquitination of hypoxia-inducible factor 
requires direct binding to the beta-domain of the von Hippel-Lindau protein. Nat. Cell Biol. 2, 423-427. https://doi.org/10.1038/35017054.

Ohnuki, H., Inoue, H., Takemori, N., Nakayama, H., Sakaue, T., Fukuda, S., Miwa, D., Nishiwaki, E., Hatano, M., Tokuhisa, T., et al. (2012). BAZF, a novel component of cullin3-based E3 ligase complex, mediates VEGFR and Notch cross-signaling in angiogenesis. Blood 119, 2688-2698. https://doi.org/10.1182/blood-2011-03345306.

Osada, M., Imaoka, S., and Funae, Y. (2004). Apigenin suppresses the expression of VEGF, an important factor for angiogenesis, in endothelial cells via degradation of HIF-1alpha protein. FEBS Lett. 575, 59-63. https:// doi.org/10.1016/j.febslet.2004.08.036.

Pan, M.R., Chang, T.M., Chang, H.C., Su, J.L., Wang, H.W., and Hung, W.C. (2009). Sumoylation of Proxl controls its ability to induce VEGFR3 expression and lymphatic phenotypes in endothelial cells. J. Cell. Sci. $122,3358-3364$.

Pasquale, E.B. (2005). Eph receptor signalling casts a wide net on cell behaviour. Nat. Rev. Mol. Cell Biol. 6, $462-475$

Piazza, F., Gurrieri, C., and Pandolfi, P.P. (2001). The theory of APL. Oncogene 20, 7216-7222.

Polunovsky, V.A., Wendt, C.H., Ingbar, D.H., Peterson, M.S., and Bitterman, P.B. (1994). Induction of endothelial cell apoptosis by TNF alpha: modulation by inhibitors of protein synthesis. Exp. Cell Res. 214, 584-594.

Pugh, C.W., and Ratcliffe, P.J. (2003). Regulation of angiogenesis by hypoxia: role of the HIF system. Nat. Med. 9, 677-684. https://doi.org/10.1038/nm0603677.

Rabellino, A., and Scaglioni, P.P. (2013). PML degradation: multiple ways to eliminate PML. Front. Oncol. 3, 60. https://doi.org/10.3389/fonc.2013.00060.

Rabellino, A., Carter, B., Konstantinidou, G., Wu, S.Y., Rimessi, A., Byers, L.A., Heymach, J.V., Girard, L., Chiang, C.M., Teruya-Feldstein, J., et al. (2012). The SUMO E3-ligase PIAS1 regulates the tumor suppressor PML and its oncogenic counterpart PML-RARA. Cancer Res. 72, 2275-2284. https://doi.org/10.1158/00085472.CAN-11-3159.

Rabellino, A., Melegari, M., Tompkins, V.S., Chen, W., Van Ness, B.G., Teruya-Feldstein, J., Conacci-Sorrell, M., Janz, S., and Scaglioni, P.P. (2016). PIAS1 promotes lymphomagenesis through MYC upregulation. Cell Rep. $15,2266-2278$.

Rabellino, A., Andreani, C., and Scaglioni, P.P. (2017). The role of PIAS SUMO E3-ligases in cancer. Cancer Res. 77, 1542-1547. https://doi.org/10.1158/0008-5472. CAN-16-2958.

Rahimi, N., and Costello, C.E. (2015). Emerging roles of post-translational modifications in signal transduction and angiogenesis. Proteomics 15, 300-309. https://doi. org/10.1002/pmic.201400183.

Rivkin, E., Almeida, S.M., Ceccarelli, D.F., Juang, Y.C., MacLean, T.A., Srikumar, T., Huang, H., Dunham, W.H., Fukumura, R., Xie, G., et al. (2013). The linear ubiquitin-specific deubiquitinase gumby regulates angiogenesis. Nature 498, 318-324. https://doi. org/10.1038/nature 12296 .
Rual, J.F., Venkatesan, K., Hao, T., Hirozane-Kishikawa, T., Dricot, A., Li, N., Berriz, G.F., Gibbons, F.D., Dreze, M., Ayivi-Guedehoussou, N., et al. (2005). Towards a proteome-scale map of the human protein-protein interaction network. Nature 437, 1173-1178.

Saitoh, H., and Hinchey, J. (2000). Functional heterogeneity of small ubiquitin-related protein modifiers SUMO-1 versus SUMO-2/3. J. Biol. Chem. 275, 6252-6258.

Sakaue, T., Maekawa, M., Nakayama, H., and Higashiyama, S. (2017). Prospect of divergent roles for the CUL3 system in vascular endothelial cell function and angiogenesis. J. Biochem. 162, 237-245. https://doi. org/10.1093/jb/mvx051.

Salomoni, P., and Pandolfi, P.P. (2002). The role of PML in tumor suppression. Cell 108, 165-170.

Scaglioni, P.P., Yung, T.M., Cai, L.F., Erdjument-Bromage, H., Kaufman, A.J., Singh, B., Teruya-Feldstein, J., Tempst, P., and Pandolfi, P.P. (2006). A CK2-dependent mechanism for degradation of the PML tumor suppressor. Cell 126, 269-283.

Semenza, G.L. (2000). HIF-1 and human disease: one highly involved factor. Genes Dev. 14, 1983-1991.

Semenza, G.L. (2012). Hypoxia-inducible factors: mediators of cancer progression and targets for cancer therapy. Trends Pharmacol. Sci. 33, 207-214. https:// doi.org/10.1016/j.tips.2012.01.005.

Shivanna, S., Harrold, I., Shashar, M., Meyer, R., Kiang, C., Francis, J., Zhao, Q. Feng, H., Edelman, E.R., Rahimi, N., et al. (2015). The c-Cbl ubiquitin ligase regulates nuclear $\beta$-catenin and angiogenesis by its tyrosine phosphorylation mediated through the Wnt signaling pathway. J. Biol. Chem. 290, 12537-12546. https://doi. org/10.1074/jbc.M114.616623.

Siebel, C., and Lendahl, U. (2017). Notch signaling in development, tissue homeostasis, and disease. Physiol. Rev. 97, 1235-1294. https://doi.org/10.1152/ physrev.00005.2017.

Siekmann, A.F., and Lawson, N.D. (2007). Notch signalling and the regulation of angiogenesis. Cell Adh. Migr. 1, 104-106.

Smith, G.A., Fearnley, G.W., Abdul-Zani, I., Wheatcroft, S.B., Tomlinson, D.C., Harrison, M.A., and Ponnambalam, S. (2016). VEGFR2 trafficking, signaling and proteolysis is regulated by the ubiquitin isopeptidase USP8. Traffic 17, 53-65. https://doi.org/10.1111/tra.12341.

Smith, G.A., Fearnley, G.W., Abdul-Zani, I., Wheatcroft, S.B., Tomlinson, D.C., Harrison, M.A., and Ponnambalam, S. (2017). Ubiquitination of basal VEGFR2 regulates signal transduction and endothelial function. Biol. Open 6, 1404-1415. https://doi.org/10.1242/bio.027896.

Soga, N., Connolly, J.O., Chellaiah, M., Kawamura, J., and Hruska, K.A. (2001a). Rac regulates vascular endothelial growth factor stimulated motility. Cell Commun. Adhes. $8,1-13$.

Soga, N., Namba, N., McAllister, S., Cornelius, L., Teitelbaum, S.L., Dowdy, S.F., Kawamura, J., and Hruska, K.A. (2001b). Rho family GTPases regulate VEGFstimulated endothelial cell motility. Exp. Cell Res. 269, 73-87. https://doi.org/10.1006/excr.2001.5295.

Steagall, R.J., Daniels, C.R., Dalal, S., Joyner, W.L., Singh, M., and Singh, K. (2014). Extracellular ubiquitin increases expression of angiogenic molecules and stimulates angiogenesis in cardiac microvascular endothelial 
cells. Microcirculation 21, 324-332. https://doi. org/10.1111/micc.12109.

Stoica, G.E., Kuo, A., Aigner, A., Sunitha, I., Souttou, B., Malerczyk, C., Caughey, D.J., Wen, D., Karavanov, A., Riegel, A.T., et al. (2001). Identification of anaplastic lymphoma kinase as a receptor for the growth factor pleiotrophin. J. Biol. Chem. 276, 16772-16779. https:// doi.org/10.1074/jbc.M010660200.

Stoica, G.E., Kuo, A., Powers, C., Bowden, E.T., Sale, E.B., Riegel, A.T., and Wellstein, A. (2002). Midkine binds to anaplastic lymphoma kinase (ALK) and acts as a growth factor for different cell types. J. Biol. Chem. 277, 3599035998. https://doi.org/10.1074/jbc.M205749200.

Suchting, S., Freitas, C., le Noble, F., Benedito, R., Bréant, C., Duarte, A., and Eichmann, A. (2007). The Notch ligand Delta-like 4 negatively regulates endothelial tip cell formation and vessel branching. Proc. Natl. Acad. Sci. U.S.A. 104, 3225-3230.

Sujashvili, R. (2016). Advantages of extracellular ubiquitin in modulation of immune responses. Mediators Inflamm. 2016, 4190390. https://doi. org/10.1155/2016/4190390.

Sun, L., and Chen, Z.J. (2004). The novel functions of ubiquitination in signaling. Curr. Opin. Cell Biol. 16, 119-126. https://doi.org/10.1016/j.ceb.2004.02.005.

Swatek, K.N., and Komander, D. (2016). Ubiquitin modifications. Cell Res. 26, 399-422. https://doi. org/10.1038/cr.2016.39.

Takagi, M., Yamauchi, M., Toda, G., Takada, K., Hirakawa, T., and Ohkawa, K. (1999). Serum ubiquitin levels in patients with alcoholic liver disease. Alcohol. Clin. Exp. Res. 23 (Suppl. 4), 76S-80S.

Tanimoto, K., Makino, Y., Pereira, T., and Poellinger, L. (2000). Mechanism of regulation of the hypoxiainducible factor-1 alpha by the von Hippel-Lindau tumor suppressor protein. EMBO J. 19, 4298-4309. https://doi.org/10.1093/emboj/19.16.4298.

Tetsu, O., and McCormick, F. (1999). Beta-catenin regulates expression of cyclin D1 in colon carcinoma cells. Nature 398, 422-426. https://doi.org/10.1038/18884.

Troilo, A., Alexander, I., Muehl, S., Jaramillo, D., Knobeloch, K.P., and Krek, W. (2014). HIF1 $\alpha$ deubiquitination by USP8 is essential for ciliogenesis in normoxia. EMBO Rep. 15, 77-85. https://doi.org/10.1002/ embr.201337688.

Tsunematsu, R., Nakayama, K., Oike, Y., Nishiyama, M., Ishida, N., Hatakeyama, S., Bessho, Y., Kageyama, R., Suda, T., and Nakayama, K.I. (2004). Mouse Fbw7/ Sel-10/Cdc4 is required for notch degradation during vascular development. J. Biol. Chem. 279, 9417-9423. https://doi.org/10.1074/jbc.M312337200.

Ucuzian, A.A., Gassman, A.A., East, A.T., and Greisler, H.P. (2010). Molecular mediators of angiogenesis. J. Burn Care Res. 31, 158-175. https://doi.org/10.1097/ BCR.0b013e3181c7ed82.

Villarroya-Beltri, C., Guerra, S., and Sánchez-Madrid, F. (2017). ISGylation - a key to lock the cell gates for preventing the spread of threats. J. Cell. Sci. 130, 29612969. https://doi.org/10.1242/jcs.205468.

Wagner, S.A., Beli, P., Weinert, B.T., Nielsen, M.L., Cox, J., Mann, M., and Choudhary, C. (2011). A proteome-wide, quantitative survey of in vivo ubiquitylation sites reveals widespread regulatory roles. Mol. Cell Proteomics
10, M111.013284. https://doi.org/10.1074/mcp. M111.013284.

Wehrle, C., Van Slyke, P., and Dumont, D.J. (2009). Angiopoietin-1-induced ubiquitylation of Tie2 by c-Cbl is required for internalization and degradation. Biochem. J. 423, 375-380. https://doi.org/10.1042/BJ20091010.

Wenger, R.H. (2002). Cellular adaptation to hypoxia: O2-sensing protein hydroxylases, hypoxia-inducible transcription factors, and O2-regulated gene expression. FASEB J. 16, 1151-1162. https://doi.org/10.1096/ f.01-0944rev.

Wing, S.S. (2003). Deubiquitinating enzymes - the importance of driving in reverse along the ubiquitinproteasome pathway. Int. J. Biochem. Cell Biol. 35, 590-605.

Wong, A., Lamothe, B., Lee, A., Schlessinger, J., Lax, I., and $\mathrm{Li}, \mathrm{A}$. (2002). FRS2 alpha attenuates FGF receptor signaling by Grb2-mediated recruitment of the ubiquitin ligase Cbl. Proc. Natl. Acad. Sci. U.S.A. 99, 6684-6689. https://doi.org/10.1073/pnas.052138899.

Wu, L.W., Mayo, L.D., Dunbar, J.D., Kessler, K.M., Baerwald, M.R., Jaffe, E.A., Wang, D., Warren, R.S., and Donner, D.B. (2000). Utilization of distinct signaling pathways by receptors for vascular endothelial cell growth factor and other mitogens in the induction of endothelial cell proliferation. J. Biol. Chem. 275, 5096-5103.

Xu, D., Yao, Y., Lu, L., Costa, M., and Dai, W. (2010a). Plk3 functions as an essential component of the hypoxia regulatory pathway by direct phosphorylation of HIF1alpha. J. Biol. Chem. 285, 38944-38950. https://doi. org/10.1074/jbc.M110.160325.

Xu, Y., Zuo, Y., Zhang, H., Kang, X., Yue, F., Yi, Z., Liu, M., Yeh, E.T., Chen, G., and Cheng, J. (2010b). Induction of SENP1 in endothelial cells contributes to hypoxiadriven VEGF expression and angiogenesis. J. Biol. Chem. 285, 36682-36688. https://doi.org/10.1074/ jbc.M110.164236.

Yamamoto, H., Ihara, M., Matsuura, Y., and Kikuchi, A. (2003). Sumoylation is involved in beta-catenindependent activation of Tcf-4. EMBO J. 22, 2047-2059. https://doi.org/10.1093/emboj/cdg204.

Yamamura, S., Nelson, P.R., and Kent, K.C. (1996). Role of protein kinase $\mathrm{C}$ in attachment, spreading, and migration of human endothelial cells. J. Surg. Res. 63, 349-354.

Yang, P., Zhang, Y., Xu, J., Zhang, S., Yu, Q. Pang, J., Rao, X., Kuczma, M., Marrero, M.B., Fulton, D., et al. (2013). SUMO1 regulates endothelial function by modulating the overall signals in favor of angiogenesis and homeostatic responses. Am. J. Transl. Res. 5, 427-440.

Yang, X., Liaw, L., Prudovsky, I., Brooks, P.C., Vary, C., Oxburgh, L., and Friesel, R. (2015). Fibroblast growth factor signaling in the vasculature. Curr. Atheroscler. Rep. 17, 509. https://doi.org/10.1007/s11883-0150509-6.

Yeh, E.T. (2009). SUMOylation and De-SUMOylation: wrestling with life's processes. J. Biol. Chem. 284, 8223-8227. https://doi.org/10.1074/jbc.R800050200.

You, Z., Saims, D., Chen, S., Zhang, Z., Guttridge, D.C., Guan, K.L., MacDougald, O.A., Brown, A.M., Evan, G., Kitajewski, J., et al. (2002). Wnt signaling promotes oncogenic transformation by inhibiting c-Myc-induced apoptosis. J. Cell Biol. 157, 429-440. https://doi. org/10.1083/jcb.200201110. 
Yu, L., Ji, W., Zhang, H., Renda, M.J., He, Y., Lin, S., Cheng, E.C., Chen, H., Krause, D.S., and Min, W. (2010). SENP1-mediated GATA1 deSUMOylation is critical for definitive erythropoiesis. J. Exp. Med. 207, 1183-1195. https://doi.org/10.1084/jem.20092215.

Yuan, W.C., Lee, Y.R., Huang, S.F., Lin, Y.M., Chen, T.Y., Chung, H.C., Tsai, C.H., Chen, H.Y., Chiang, C.T., Lai, C.K., et al. (2011). A Cullin3-KLHL20 Ubiquitin ligase-dependent pathway targets PML to potentiate HIF-1 signaling and prostate cancer progression. Cancer Cell 20, 214-228. https://doi.org/10.1016/j. ccr.2011.07.008.

Zerlin, M., Julius, M.A., and Kitajewski, J. (2008). Wnt/ Frizzled signaling in angiogenesis. Angiogenesis 11, 63-69. https://doi.org/10.1007/s10456-008-9095-3.
Zhang, C., Li, Y., Cornelia, R., Swisher, S., and Kim, H. (2012). Regulation of VEGF expression by HIF-1 1 in the femoral head cartilage following ischemia osteonecrosis. Sci. Rep. 2, 650. https://doi.org/10.1038/srep00650.

Zhou, H.J., Xu, Z., Wang, Z., Zhang, H., Simons, M., and Min, W. (2018). SUMOylation of VEGFR2 regulates its intracellular trafficking and pathological angiogenesis. Nat. Commun. 9, 3303. https://doi.org/10.1038/ s41467-018-05812-2.

Zhu, X., Ding, S., Qiu, C., Shi, Y., Song, L., Wang, Y., Wang, Y., Li, J., Wang, Y., Sun, Y., et al. (2017). SUMOylation negatively regulates angiogenesis by targeting endothelial NOTCH signaling. Circ. Res. 121, 636-649. https://doi.org/10.1161/CIRCRESAHA.117.310696. 
